Paper No. 21, entitled The Staffing of Public Health and Outpatient Nursing Services, Methods of Study*, Miss Doris E. Roberts, Nurse Consultant to the United States Public Health Service, has tackled the social and other complex factors involved.

Emphasizing the health services for patients who are not in hospital, Miss Roberts has produced a guide to methods of study of the problem which is designed to help all kinds of public health services, including hospitals, to determine the number and composition of the nursing staff they will require in order to provide efficient and economical nursing for the communities they serve. Successive chapters deal with the principles of staffing, factors which influence the pattern of staffing and methods of estimating the staff requirements. Examples are givon of the forms used for the study of time and activity involved and the progress of patients, and one section

* World Health Organization. Public Health Papers No. 21: The Staffing of Public Health and Outpatient Nursing Services. By Doris E. Roberts Pp. 101. (Geneva: World Health Organization; London: H.M.S.O.,
1963.) 4 Sw. francs; $68.8 d$.; 1.25 dollars. gives a useful guide to the establishment of nursing services where these do not exist. A bibliography completes a useful and well-printed monograph which should be useful to all who have these difficult problems in hand.

Analyses of the financial cost of the kind of planning suggested and of the total cost of the services provided were apparently not within the scope of this enquiry. Nor was the difficult problem of the recruitment of nurses, nor the inadequate salaries paid for the devoted and essential services that nurses render. Everyone who has worked in a hospital, or has been in one as a patient, will surely agree that nurses of all grades should be paid much more than they can, even in these days of high wages, expect. Hospitals could not function without their nursing staff, and it should bo recognized, without delay, that the nursing profossion is a highly skilled vocation which should be rewarded with salaries that are commensurate with the devoted services performed.

G. LAPAGE

\title{
UNIFORM METHODS OF SUGAR ANALYSIS
}

\begin{abstract}
$7 \mathrm{HE}$ origin of the International Commission for Uniform Methods of Sugar Analysis goes back to 1897 when an international meeting was convened in Hamburg in order to attempt to smooth out differences which had arisen in international trade over the determination of the sugar content in raw sugar. It soon became obvious that a standardization of methods of analysis would have to come first and this led to the foundation of the International Commission, to which twenty-one countries were affiliated in 1962 .

Progress in science and technology makes it necessary for a permanent organization to review the position from time to time and to recommend improved definitions and methods for use in the laboratories of the sugar industry. Despite the efforts of the International Commission for Uniform Methods of Sugar Analysis over many years, the situation is characterized by the following quotation from the report of the proceedings of the thirteenth session*, concerning "Ash" (p. 7): "Uniformity in expressing results is obviously lacking, and although local customs and preference are strong factors it is felt that this 13th Session should strongly stress the desirability of endeavouring to attain uniformity". This situation is
\end{abstract}

further illuminated in the discussion of such an important subject as "Reducing Sugars" (p. 15): "the difficulty is pointed out of having too many ICUMSA methods . . . , it was about time to reduce the number . . . and to put an end to the reigning confusion; . . . it was often very difficult to recommend definitely one method to the exelusion of all other methods; . . . it is proposed that an additional recommendation be made to inaugurate studies for the purpose of a possible selection of official methods".

While battling with these general difficulties, the report deals with many specific problems under 29 subject headings, and it is probably true to say that, whereas highly accurate analyses are possible, the methods are often too cumbersome for routine application and in many cases "sampling presents the most difficult problem" (p. 113).

J. EISNER

* International Commission for Uniform Methods of Sugar Analysis. Report of the Proceedings of the Thirteenth Session held at the University of Iramburg and at the Atlantic Hotel, Hamburg, Germany, from August 26 to August 31, 1962. Pp. vii +125. (Keston, Kent : International Commission for Uniform Methods of Sugar Analysis; Paris: Syndicat National de Fabricants de Sucre de France; New York: Sugar Research Foundation Inc., 1963.) $28 \mathrm{~s}$.; $19 \mathrm{NF} ; 4$ dollars.

\section{OPTICAL AND IONOSPHERIC OBSERVATIONS ON THE ACTIVITY OF THE SOLAR CENTRE OF SEPTEMBER 1963}

\author{
By Prof. M. ANASTASSIADIS, Dr. D. ILIAS and Dr. C. CAROUBALOS \\ lonospheric Institute
}

AND

\author{
Dr. C. MACRIS and D. P. ELIAS
}

Astronomical Institute, National Observatory of Athens

\begin{abstract}
GOLLOWING a period of relative calm, intense solar activity occurred during the period September 13--30, 1963. In this article we report briefly the optical and radioelectric observations as well as certain geophysical observations carried out at the National Observatory of Athens, comparing them, where possible, with those of November 1960 (ref. 1) and discussing the most typical observed events.
\end{abstract}

A solar activity centre appeared on the west limb on Septembor 13 at about 1500 U.T. $\left(B=12 \cdot 6^{\circ}\right.$ N., $\mathrm{L}=311^{\circ}$, Mac Math region 6964) while an older centre was developing on the solar disk $\left(B=105^{\circ}, \mathrm{L}=90^{\circ}\right.$, Mac Math region 6961). Centre 6964 reached a maximum area on September 21 estimated at $1190 \times 10^{-6}$ of the surface of the solar hemisphere. Its optical configuration was of type $H$ and it had a 'plage filament'. The microwave 